\title{
INJURY-INDUCED NEURONOTROPHIC ACTIVITY IN ADULT RAT BRAIN: CORRELATION WITH SURVIVAL OF DELAYED IMPLANTS IN THE WOUND CAVITY ${ }^{1}$
}

\author{
M. NIETO-SAMPEDRO, ${ }^{* 2}$ M. MANTHROPE $\ddagger$ G. BARBIN $\ddagger$ S. VARON, $\ddagger$ AND C. W. COTMAN* \\ *Department of Psychobiology, University of California at Irvine, Irvine, California 92717 and $\$$ Department of Biology, School of \\ Medicine, University of California at San Diego, La Jolla, California 92093
}

Received March 17, 1983; Accepted May 9, 1983

\begin{abstract}
Mechanical or chemical injury to adult rat brain elicited the accumulation in the affected area of trophic activity for cultured parasympathetic, sympathetic, and sensory neurons. Neuronotrophic activity was relatively low both in noninjured brain tissue extracts and in extracts prepared from the tissue surrounding an injury immediately after the lesion was made. However, trophic titers increased considerably over time, first in the brain tissue that formed the walls of the wound and then in the Gelfoam filling the wound cavity. In the tissue adjacent to the injury, trophic titers began to rise immediately after the lesion, reached a maximum 10 days later, and decayed thereafter. In the wound cavity, occupied by Gelfoam, neuronotrophic activity began to increase 6 days postlesion, reached a maximum at day 16 after injury, and decreased at later times. The levels of induced trophic activity appeared to be proportional to the size of the wound. Injury to various brain areas including temporal, entorhinal, occipital, parietal, and frontal cortices, hippocampus, corpus striatum, and cerebellum, all induced a similar increase in neuronotrophic factor(s). Damage to the myelinated fibers of the corpus callosum did not. High trophic titers decayed rapidly with distance from the wound except in areas heavily deafferented by the lesion, where activity also reached high levels. Extracts from all of the above-mentioned brain areas contained toxic activity for cultured spinal cord neurons. The level of neuronotoxic activity was similar both before the lesion and 15 days postlesion, with the possible exception of the corpus callosum.

Intraventricular injections of kainic acid at doses which destroy areas CA4, CA3, and part of CA1 of the hippocampus also induced a time-dependent rise of neuronotrophic activity in this structure, comparable to that achieved by mechanical damage. Both kainic acid treatment and mechanical injury cause extensive glial proliferation in the injured and/or deafferented area. The apparent concurrence of glial reaction and increase in neuronotrophic activity suggests that glial cells may be a major source of the induced trophic activity.

As an in vivo correlate of cell culture data, the survival of striatal transplants into host cortical wounds was examined. Fragments of embryonic corpus striatum did not survive when transplanted into a freshly made cavity in the entorhinal/occipital cortex of adult rats. Survival was enhanced by introducing a delay between the time at which the wound cavity was made and that at which the striatal tissue was implanted in it. The delay period for optimal implant survival coincided with the time at which neuronotrophic activity in extracts of the tissue surrounding the wound was maximal. The relative contributions of injury-induced trophic factor(s) and other critical variables to the enhanced survival of the implants are discussed.
\end{abstract}

Serious injury to the adult central nervous system (CNS) results in the death of the neurons directly af-

\footnotetext{
${ }^{1}$ We wish to thank Miss Janel Larson for excellent technical assistance. This work was supported in part by Grants AG-00538 and MH19691 from the National Institute on Aging and National Institute of Mental Health, respectively, to C. W. C., Grant NS-16349 from National Institute of Neurological and Communicative Disorders and
}

fected by the lesion and the destruction of the connections in which they are involved. As a sequel to the injury, a second group of neurons dies at a later time,

Stroke and Grant BNS-81-18847 from the National Science Foundation to S. V., and a grant from the California Cancer Research Coordinating Committee to M. N-S.

${ }^{2}$ To whom correspondence should be addressed. 
probably as a consequence of axotomy, deafferentation, and/or ischemia. The circuitry lost through injury is partly replaced by a massive sprouting response of nondamaged axons during the evoked process of reactive synaptogenesis (Cotman and Nadler, 1978; Cotman et al., 1981). However, the molecular mechanisms that determine the survival or death of axotomized neurons as well as those that mediate the sprouting of both damaged and undamaged axons are unknown.

When large numbers of neurons are lost and major pathways are interrupted, damage repair depends on external intervention. Recently, the potential utility of transplants of donor CNS tissue, both to replace the neurons lost and as relay stations for regenerating host axons, has become evident. However, for implants to be useful in these capacities it is necessary to optimize their survival in the host. CNS, a problem that has not been solved so far.

Recent work from our laboratories has shown that injury to both peripheral and central nervous tissue causes the appearance at the lesion site of substances capable of promoting the survival in culture of a variety of neuronal types of peripheral and central origin (NietoSampedro et al., 1982b; Lundborg et al., 1982; Manthorpe et al., 1983; Longo et al., 1983). In the developing brain, the increase with time in trophic activity at the lesion site parallels the enhancement of implant survival observed when fragments of embryonic brain are implanted at various times after the wound cavity is made. In this paper we report that mechanical or chemical damage to the adult rat CNS also induces appearance of neuronotrophic activity at the injury site. The induced neuronotrophic activity correlates with the enhanced survival of striatal fragments implanted in the injury area and points to ways of optimizing survival of implants in adult CNS.

\section{Materials and Methods}

Surgery and histology. The experimental subjects were young adult (60 to 90 days old) Sprague-Dawley male rats purchased from Simonsen Laboratories (Gilroy, CA) or bred and raised in the vivarium facilities of the university. All operations were carried out under sodium pentobarbital (Nembutal) anesthesia $(50 \mathrm{mg} / \mathrm{kg})$. Mechanical wounds were inflicted by vacuum aspiration of about $10 \mathrm{~mm}^{3}$ (small wound) or $30 \mathrm{~mm}^{3}$ (standard wound volume) of the desired brain area. When that area was located beneath the neocortex (i.e., corpus striatum, hippocampus, corpus callosum), then an area of about 10 $\mathrm{mm}^{2}$ of overlying cortex was also ablated. The wound cavity was filled with Gelfoam (The Upjohn Co., Kalamazoo, MI) moistened in sterile physiological saline (American McGaw, Irvine, CA). After the desired period postlesion the animals in each group (threc to six rats per group) were anesthetized with ether and killed by decapitation, and Gelfoam fragments and relevant brain tissue were removed and pooled separately. Fragments of Gelfoam collected 1 to $2 \mathrm{hr}$ postoperation were denominated "time zero" Gelfoam. 'Time zero brain tissue samples were collected from the relevant brain areas of nonoperated animals. All other samples were obtained at the postlesion times indicated in the text. Neurono- trophic activity was assayed on extracts prepared from tissue or Gelfoam as described below. In a parallel study we also determined the activity that appeared in the Gelfoam in the interval between various postlesion times; i.e., between days 1 and 4, days 3 to 6 , etc. To sample, for instance, the trophic activity released between days 3 and 6 postlesion, the Gelfoam implanted at the time of the lesion (day 0) was removed under ether anesthesia at day 3 and a fresh Gelfoam fragment was placed in the cavity. This second Gelfoam fragment was retrieved at day 6 postlesion and was used to measure the neuronotrophic factors secreted in the interval between 3 and 6 days.

Bilateral intraventricular injection of kainic acid (0.8 $\mu \mathrm{g} /$ ventricle; Nadler et al., 1978) and complete unilateral transection of the fimbria (Moore et al., 1971) were carried out as described previously (Nieto-Sampedro et al., 1982a).

The surgical paradigm used for brain tissue transplantation was similar to that used for the study of the time course of trophic factor accumulation. A unilateral cavity of about $30 \mathrm{~mm}^{3}$ was aspirated in the cortex of adult rats to ablate part of the entorhinal cortex and transect the angular bundle exposing (but not damaging) the dorsal surface of the hippocampus. Although the occipital and temporal cortices were also damaged, this operation will be designated "entorhinal ablation." During the same operation the rats also received a complete unilateral fimbria transection, and both wounds were filled with saline-moistened Gelfoam. After the desired period of delay $(0,4,8,13,16$, and 20 days) several small fragments ( 0.5 to $2 \mathrm{~mm}^{3}$ each; total tissue volume implanted, 6 to 9 $\mathrm{mm}^{3}$ ) of 18-day embryonic corpus striatum were placed in the entorhinal cavity below the Gelfoam, directly apposed to the dorsal surface of the host hippocampus. Each implanted group consisted of four to eight animals. Corpus striatum was selected as the grafted tissue because its survival in entorhinal wound cavities depended strongly on allowing a delay in implantation after making the receiving cavity (Lewis and Cotman, 1983). Thirty days after implantation the animals were perfused through the heart with saline followed by fixative ( $4 \%$ formaldehyde in saline solution). The brains were removed, postfixed in $2 \%$ formaldehyde ( 8 to $16 \mathrm{hr}$ ), and sectioned in a freezing microtome. Serial horizontal or coronal sections ( 40 to $50 \mu \mathrm{m}$ ) were stained for acetylcholinesterase (Naik, 1963) in the presence of inhibitors for nonspecific cholinesterase (Lewis and Cotman, 1980), and alternate sections were counterstained with cresyl violet. The volume of surviving implanted tissue was estimated from its area in each serial section and the known number and thickness of the sections.

Preparation of neuronotrophic extracts. Gelfoam fragments (20 to $40 \mathrm{~mm}^{3}$ ) were removed from the relevant brain area within 5 min of the death of the animal and frozen at $-76^{\circ} \mathrm{C}$, as were samples of tissue adjacent to the wound (to a depth of 1 to $2 \mathrm{~mm}$ into the walls of the wound cavity), as well as tissue located far away from and unconnected to the damaged area. Tissue samples (20 to $60 \mathrm{~mm}^{3} /$ animal) and Gelfoam were thawed and homogenized at $4^{\circ} \mathrm{C}$ in sterile PBS (25 mM sodium phosphate $/ 0.15 \mathrm{M}$ sodium chloride, $\mathrm{pH} 7.2$ ) by 20 up and 
down strokes of a tight-fitting Teflon pestle in a PotterElvehjem homogenizer. The volume of PBS used for the homogenization was $100 \mu \mathrm{l} /$ sample for Gelfoam fragments and twice their packed volume for brain tissue samples. The homogenates were centrifuged at $10,000 \times$ $g$ for $15 \mathrm{~min}$, the supernatants (trophic extracts) were collected, and aliquots were stored at $-76^{\circ} \mathrm{C}$ until assay. The extracts were then thawed, diluted at least 10 -fold with culture medium (serum-supplemented, modified Eagle's basal medium as described by Varon et al., 1981), and assayed in vitro for their ability to support neuron survival.

Assays for neuronotrophic and neuronotoxic activities. Titration of trophic activity in the extracts was carried out by a miniaturized procedure on the $6-\mathrm{mm}$-diameter wells of 96-well microtiter plates in a final volume of 100 $\mu \mathrm{l}$, as previously described (Manthorpe et al., 1981, 1983). Each microwell received $50 \mu \mathrm{l}$ of serially diluted test sample and $50 \mu \mathrm{l}$ of neuronal cell suspension. Neuronal cell suspensions were derived from the following tissue dissociates: neonatal mouse dorsal root ganglion (mDRG; 40,000 cells $/ \mathrm{ml}$ ), day 11 chick embryo sympathetic ganglia (cSG12; 40,000 cells/ml), day 8 chick embryo ciliary ganglion (cCG8; 40,000 cells/ml; Manthorpe et al., 1980; Varon et al., 1981), and day 4 chick embryo spinal cord (cLC4; 20,000 cells/ml; Longo et al., 1982). All assays included negative control cultures unsupported by exogenous factors, the survival values of which (usually less than $15 \%$ maximal survival) were subtracted from the experimental values, as well as positive control cultures supported by an excess of the relevant growth factor (final concentrations: 100 trophic units $/ \mathrm{ml}$ of nerve growth factor for $\mathrm{mDRG}$ and $\mathrm{cSG} 12 ; 100$ units $/ \mathrm{ml}$ of eye-derived ciliary neuronotrophic factor for cCG8; and $25 \%$ of RN22 schwannoma-conditioned medium for cLC4 cells) to determine maximal survival levels. One unit of trophic activity (1 TU) is defined as the activity that, when present in $1 \mathrm{ml}$ of medium, allows $50 \%$ of the maximal possible neuronal survival (Manthorpe et al., 1980; Varon et al., 1981).

A similar microassay was developed to measure neuronotoxic activity on cLC4 neurons (Manthorpe et al., 1982) and used here to determine the toxic activity for these cells present in Gelfoam or tissue extracts. Spinal cord neurons ( $1000 \mathrm{cLC} 4$ cells/microwell), maximally supported with schwannoma-conditioned medium, were cultured for $24 \mathrm{hr}$ with decreasing concentrations of test extract and the resulting survival values compared to those for maximally supported controls. One unit of neuronotoxic or survival-interfering activity (1 IU) is defined as the activity per milliliter of culture medium that reduces by $50 \%$ the $24 \mathrm{hr}$ survival of maximally supported cLC4 cells (Manthorpe et al., 1982).

Calculation of specific neuronotrophic and neuronotoxic activities. Values of specific neuronotrophic or neuronotoxic activity in Gelfoam and brain tissue may be expressed in at least three manners: (i) as trophic or toxic units in each Gelfoam or tissue sample (i.e., units per wound or per animal); (ii) as units per unit volume $\left(\mathrm{mm}^{3}\right)$ of packed (centrifuged at $10,000 \times g, 5$ min) Gelfoam or tissue; or (iii) as units per milligram of protein in Gelfoam or brain tissue. All three expressions are open to criticism; for example, induced trophic activity depends on the precise size of the wound (see "Results") and therefore measure $i$ seems inadequate. The accuracy of measure ii depends on an accurate volume determination which, in turn, is influenced by the volume of air trapped by samples. The accuracy of measure iii can be jeopardized by blood contamination of both Gelfoam and tissue, mainly at the early time points, and be cell invasion of the Gelfoam at late time points. Both expressions $i i$ and iii are directly influenced by the sampling process itself: dry Gelfoam samples can easily be cut to a desired volume, but it is rather more difficult to sample identical volumes of fresh brain tissue. By keeping as constant as possible the volume of the tissue removed to inflict the wound, the volume of Gelfoam filling the wound cavity, and the volume of tissue sample dissected, similar time course curves were obtained from the values derived from all three expressions. We have used expression $i i$ throughout the paper.

Protein determination. Protein content was estimated as described by Bradford (1976) using bovine serum albumin as standard.

Reagents. Eagle's basal medium (powdered form) and fetal calf serum were purchased from Grand Island Biological Co. (Grand Island, NY), and trypsin was purchased from Calbiochem-Behring Corp. (San Diego, CA). Nerve growth factor, eye-derived ciliary neuronotrophic factor, and R22 schwannoma-conditioned medium were prepared according to previously published procedures (Varon et al., 1972, 1981; Manthorpe et al., 1980). All other chemicals were analytical reagent grade or the best grade commercially available.

\section{Results}

Neuronotrophic activity in adult brain wounds. The level of trophic activity in wounds in the adult rat brain was examined at various intervals postlesion following ablation of about $30 \mathrm{~mm}^{3}$ of "entorhinal" (see "Materials and Methods") cortex. The time course of appearance of trophic activity in Gelfoam and brain tissue extracts was tested on three types (parasympathetic, sympathetic, and sensory) of ganglionic neurons (Fig. 1). Specific neuronotrophic activity in the extracts was expressed as trophic units per cubic millimeter of originally packed Gelfoam or tissue, but similar curves were obtained if results were calculated as trophic units per milligram of protein or trophic units per wound. The volume and protein content of the pooled samples for each time point in Figure 1 are given in Table I to facilitate calculation of specific activity in alternative units.

The trophic activity found in Gelfoam extract $2 \mathrm{hr}$ postlesion was negligible and remained very low during the first 4 days postlesion (Fig. 1). It began to rise by day 6 postlesion and reached a maximum at day 16 after injury. The neuronal cell target specificity profile of the trophic activity in Gelfoam was similar to that found when injury was inflicted in neonatal rat brain (NietoSampedro et al., 1982b, Manthorpe et al., 1983); i.e., was most active for sympathetic ganglion cells (Fig. 1b) and about one order of magnitude lower on ciliary and dorsal root ganglionic neurons (Fig. 1, $a$ and $c$ ).

In previous studies using neonatal animals (Nieto- 

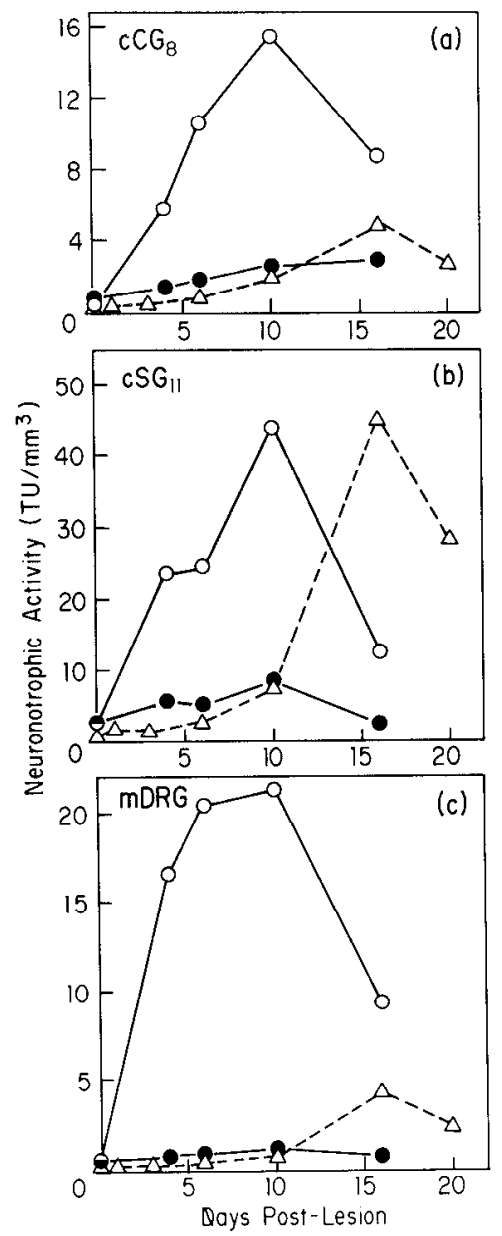

Figure 1. Tine course of appearance of neuronotrophic activity after injury to the adult rat brain cortex. A unilateral cavity of about $30 \mathrm{~mm}^{3}$ was vacuum aspirated in the "entorhinal" (see "Materials and Methods") cortex and the wound was filled with a fragment of saline-moistened Gelfoam. At various times postlesion neuronotrophic activity was determined in extracts of: $\Delta--\Delta$, Gelfoam; $\mathrm{O}-\mathrm{O}$, the tissue immediately adjacent to the wound, i.e., that forming the walls of the wound cavity; - contralateral frontal cortex (uninjured tissue, far away from and unconnected to the injured cortex). The test neurons were dissociated cultures of 8-day chick embryo ciliary ganglia $\left(c C G_{8}\right), 11$-day chick embryo sympathetic ganglia $\left(c S G_{11}\right.$ ), and neonatal mouse dorsal root ganglia $(m D R G)$. Samples were pooled from three to six animals per time point and three independent determinations were carried out in duplicate on each pool. Maximum deviations fell within $20 \%$ of the reported values.

Sampedro et al., 1982b; Manthorpe et al., 1983), accumulation of trophic activity was only measured in the Gelfoam that filled the wound cavity. In the present study we measured the trophic activity in both the Gelfoam and the brain tissue that formed the walls of the wound cavity. Extracts of control tissue from the same brain region of noninjured animals (day 0 samples) and tissue of injured animals from a brain region removed from and unconnected to the injured cortex (contralateral frontal cortex) were also examined. The results (Fig. 1) indicate that the observed increase in neuronotrophic levels was injury-induced. Normal adult brain tissue
TABLE I

Packed volume and protein content of Gelfoam and brain tissue samples at various times postlesion

The values given for each combined pool of samples are the average of two independent determinations. Maximum deviations were within $\pm 15 \%$ of the values reported.

\begin{tabular}{|c|c|c|c|c|c|c|c|}
\hline \multirow{3}{*}{$\begin{array}{c}\text { Postlesion } \\
\text { Day }\end{array}$} & \multirow{3}{*}{$\begin{array}{c}\text { No. of } \\
\text { Samples }\end{array}$} & \multicolumn{2}{|c|}{ Gelfoam } & \multicolumn{4}{|c|}{ Tissue } \\
\hline & & \multirow{2}{*}{$\begin{array}{l}\text { Volume } \\
\left(\mathrm{mm}^{3}\right)\end{array}$} & \multirow{2}{*}{$\begin{array}{c}\text { Protein }^{b} \\
\text { (mg) }\end{array}$} & \multicolumn{2}{|c|}{ Adjacent } & \multicolumn{2}{|c|}{ Far } \\
\hline & & & & $\begin{array}{c}\text { Volume } \\
\left(\mathrm{mm}^{3}\right)\end{array}$ & $\begin{array}{l}\text { Protein } \\
(\mathrm{mg})\end{array}$ & $\begin{array}{c}\text { Volume } \\
\left(\mathrm{mm}^{3}\right)\end{array}$ & $\begin{array}{l}\text { Protein } \\
\text { (mg) }\end{array}$ \\
\hline 0 & 6 & 140 & 10.2 & 100 & 6.8 & 100 & 6.8 \\
\hline 1 & 4 & 250 & 10.5 & & & & \\
\hline 3 & 3 & 130 & 3.7 & & & & \\
\hline 4 & 4 & & & 230 & 10.0 & 200 & 7.3 \\
\hline 6 & 4 & 160 & 5.2 & 70 & 4.8 & 80 & 3.6 \\
\hline 10 & 4 & 340 & 7.9 & 180 & 9.4 & 150 & 7.6 \\
\hline 16 & 3 & 200 & 5.1 & 180 & 7.4 & 150 & 6.8 \\
\hline 20 & 4 & 200 & 4.3 & & & & \\
\hline
\end{tabular}

${ }^{a}$ Packed volume was the estimated volume of the Gelfoam or tissue after centrifugation at $10,000 \times g$ for $5 \mathrm{~min}$.

${ }^{b}$ Protein was the content per pool of samples of Gelfoam or tissue extract.

(time zero tissue) had very low trophic activity, yet it was 10 to 40 times higher than that of 2 -hr Gelfoam. After injury, the trophic activity in the tissue surrounding the wound displayed a sharp increase and rose soon after the lesion to values much higher than those observed in Gelfoam (Fig. 1, $a$ to $c$ ). The activity in the tissue adjacent to the wound reached a maximum, at day 10 postlesion, which was at least one order of magnitude higher than that present in noninjured tissue and several hundredfold higher than the level in 2-hr Gelfoam. Trophic activity in tissue away from the wound also increased to some extent, but its overall level remained below the maximum in Gelfoam (Fig. 1).

The increased levels of neuronotrophic activity with time postlesion cannot be related to an increase in the protein content of the extracts. In fact, the protein content of Gelfoam samples that had remained in the wound 3 days or longer showed a large decrease with respect to earlier time samples, whereas the protein content of tissue extracts did not change significantly (Table I).

Trophic activity accumulating in extracts of Gelfoam taken at various intervals postlesion was also measured. The Gelfoam fragment initially placed in the wound was replaced by a fresh one after the desired number of days postlesion. The new sponge was retrieved after the lapse of an appropriate interval and its activity was determined (Table II, A). For comparison, the increments in trophic activity for the same time intervals were calculated, using the data in Figure 1, for a Gelfoam sponge that remained in the wound cavity from day 0 to the end of the interval (Table II, B). After the first day postlesion, the trophic activities accumulated in the Gelfoam for any given time interval were always higher in the fresh sponges placed at the beginning of the interval than in those maintained in the wound from the day of injury, with the exception of sympathetic ganglion cells in the 10- to 16-day interval (Table II). Two possible explanations for these results are that either the replacement of the original Gelfoam 
TABLE II

Accumulation of neuronotrophic acitivity in Gelfoam sponges at various intervals postlesion

Columns A: Neuronotrophic activily accumulated by Gelfoam fragments placed in the wound at the beginning of the time interval and removed at the end of it. Columns B: Neuronotrophic activity accumulated during the same interval by Gelfoam sponges that remained in the wound from day 0 to the end of the interval. These values were calculated from the data plotted in Figure 1. Maximum deviations in duplicate trophic titer determinations for each sample pool fell within $10 \%$ of the values reported.

\begin{tabular}{|c|c|c|c|c|c|c|}
\hline \multirow{3}{*}{$\begin{array}{l}\text { Interval } \\
\text { Postlesion } \\
\text { (days) }\end{array}$} & \multicolumn{6}{|c|}{ Trophic Units per $\mathrm{mm}^{3}$ of Packed Gelfoam } \\
\hline & \multicolumn{2}{|c|}{ cCG8 } & \multicolumn{2}{|c|}{ cSG11 } & \multicolumn{2}{|c|}{$\mathrm{mDRG}$} \\
\hline & $\mathrm{A}$ & $\mathrm{B}$ & A & $\mathrm{B}$ & $\mathrm{A}$ & B \\
\hline $0-1$ & 0.2 & 0.2 & 1.8 & 1.8 & 0.2 & 0.2 \\
\hline $1-3$ & 2.3 & 0.05 & 9.3 & -0.2 & 1.7 & 0.04 \\
\hline $3-6$ & 3.7 & 0.6 & 9.8 & 1.3 & 2.0 & 0.2 \\
\hline $6-10$ & 4.1 & 1.1 & 32.1 & 4.6 & 2.0 & 0.2 \\
\hline $10-16$ & 7.5 & 2.9 & 22.5 & 41.9 & 5.1 & 3.6 \\
\hline Total $(0-16)$ & 17.8 & 4.85 & 75.5 & 49.4 & 11.0 & 4.24 \\
\hline
\end{tabular}

fragment by a fresh one triggered an increase in the secretory activity of the tissue surrounding the sponge, or the trophic factors absorbed in the gelfoam were gradually inactivated.

Titration of Gelfoam extracts using chick embryo lumbar spinal cord neurons (cLC4) revealed the simultaneous presence in the wound fluid from neonatal rats of both neuronotrophic and neuronotoxic activities (Manthorpe et al., 1983). Tissue extracts from both normal adult rat brain tissue and tissue adjacent to the injury site displayed even higher levels of toxicity (2 to 7 neuronotoxic units $/ \mathrm{mm}^{3}$ of tissue), precluding the quantitative determination of trophic titers on spinal cord neurons.

Influence of distance from the wound on the neuronotrophic activity of brain tissue. To determine the trophic activity present at various distances from the wound in areas connected or unconnected to the lesion site, a group of animals received an ablation of about $10 \mathrm{~mm}^{2}$ of occipital/temporal cortex surface, to the depth necessary to destroy the angular bundle without damaging the adjacent hippocampus. Fifteen days postlesion neuronotrophic activity for cCG8 neurons was examined in cxtracts of equally thick slices of cortex collected at increasing distances from the wound in both the ipsilateral (posterior-anterior direction, Fig. 2) and contralateral cortex (medial-lateral with respect to the wound, Fig. 2), and in the hippocampus (both ipsilateral and contralateral to the lesion). In the neocortical tissue ipsilateral to the lesion the trophic activity decayed rapidly at increasing distances from the wound (Fig. 2). However, the trophic titer in the tissue taken furthest from the wound was still 2-fold higher than the basal levels in noninjured animals, suggesting that some spread of trophic activity, perhaps through the ventricular system, had taken place. The cortical tissue contralateral to the wound, that was only sparsely connected to the damaged area, also had levels of trophic activity slightly higher than the corresponding noninjured tissue controls (Fig. 2).

The lesion used here destroyed the perforant path,

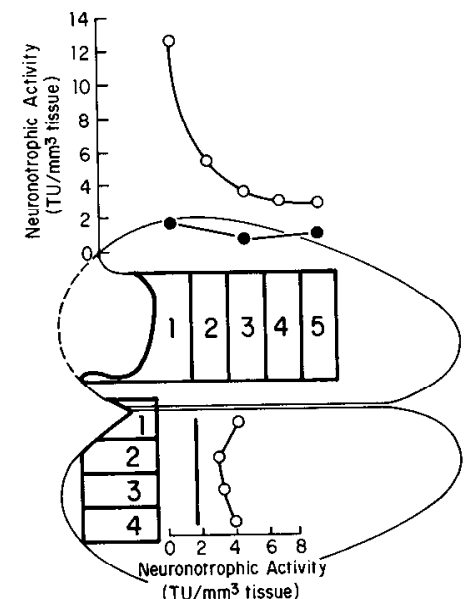

Figure 2. Injury-induced neuronotrophic activity as a function of the distance from the lesion site. A unilateral wound was made in the occipital/temporal cortex of four adult rats. Neuronotrophic activity for cCG8 neurons $(O)$ was determined 15 days later in pooled extracts of 2 -mm-thick slices of cortical tissue taken at increasing distances from the injury site, both within the same cerebral hemisphere (posterior-anterior direction) and in the opposite hemisphere (locus symmetrical to the wound). Maximum deviations of duplicate determinations for each pool always fell within $10 \%$ of the values reported. Trophic titers in equivalent tissue from noninjured animals (O) are given for comparison.

thus heavily deafferenting the hippocampal dentate gyrus ipsilateral to the lesion (Matthews et al., 1976). The trophic activity in the whole ipsilateral hippocampal formation, examined in a pooled group of four animals, was $11 \mathrm{TU} / \mathrm{mm}^{3}$ of packed tissue. This value can be compared to $8 \mathrm{TU} / \mathrm{mm}^{3}$ in the lightly deafferented (Steward, 1976) contralateral hippocampus and $5 \mathrm{TU} / \mathrm{mm}^{3}$ for the basal hippocampal level in normal animals.

Influence of wound size on induced neuronotrophic specific activity. Two groups of rats that received unilateral ablations of either $10 \mathrm{~mm}^{3}$ or $30 \mathrm{~mm}^{3}$ of parietal cortical tissue were used to examine the influence of wound size on the level of induced trophic activity for cCG8 cells. Fifteen days postlesion the Gelfoam that filled the wound and the tissue that formed the walls of the wound cavity were analyzed for neuronotrophic activity. The smaller wound induced a lower level of trophic activity and the titers were all roughly proportional to the volume of the cavity made (Table III).

Injury-induced trophic activity in different brain areas. Wounds of similar size (about $30 \mathrm{~mm}^{3}$ ) were made in the brain of adult rats in the following loci: frontal and parietal cortices (avoiding damage of the underlying corpus callosum); entorhinal cortex (damaging part of the occipital and temporal cortices); parietal cortex and underlying corpus callosum; corpus striatum; hippocampal formation; and cerebellar cortex. To obtain trophic factors from corpus callosum injuries, two Gelfoam fragments were inserted: the first, that was used for assay, was in contact with the damaged fibers; the second, not used for assay, was placed over the first, filling the ablated cortical cavity immediately above the injured fibers. After 15 days Gelfoam and the tissue adjacent and 
TABLE III

Influence of the size of the wound on the induced trophic activity

Determinations of neuronotrophic activity were carried out using cCG8 neurons. Pooled samples from two groups of four rats each were tested 15 days after a cavity of the indicated volume had been made in the parietal cortex of the animals. Maximum deviations of duplicate titrations fell within $10 \%$ of the values reported.

\begin{tabular}{|c|c|c|c|c|c|}
\hline \multirow{2}{*}{$\begin{array}{l}\text { Wound Volume } \\
\qquad\left(\mathrm{mm}^{3}\right)\end{array}$} & \multirow{2}{*}{$\begin{array}{l}\text { Relative } \\
\text { Volume }\end{array}$} & \multicolumn{2}{|c|}{$\begin{array}{l}\text { Neuronotrophic } \\
\text { Activity (TU/mm } \\
\text { packed sample) }\end{array}$} & \multicolumn{2}{|c|}{ Relative Activity } \\
\hline & & Gelfoam & $\begin{array}{c}\text { Adjacent } \\
\text { tissue }\end{array}$ & Gelfoam & $\begin{array}{c}\text { Adjacent } \\
\text { tissue }\end{array}$ \\
\hline 10 & 1.0 & 2.5 & 3.2 & 1.0 & 1.0 \\
\hline 30 & 3.0 & 8.4 & 7.0 & 3.4 & 2.2 \\
\hline
\end{tabular}
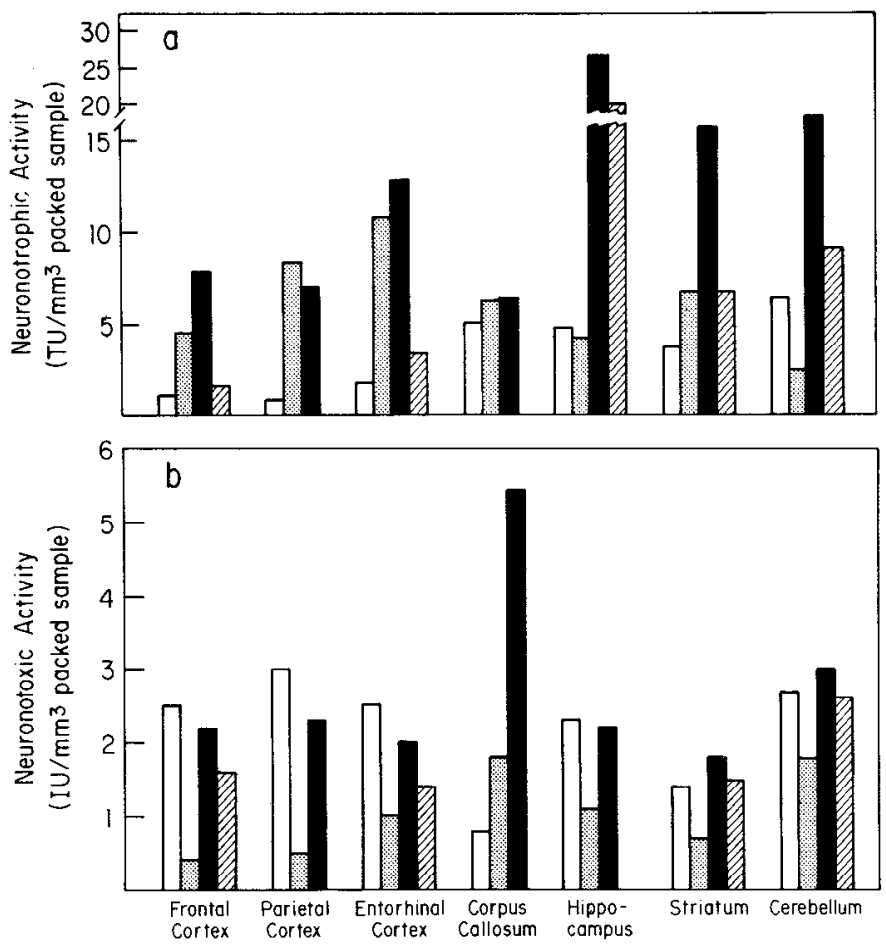

Figure 3. Injury-induced neuronotrophic $(a)$ and neuronotoxic $(b)$ activities in various adult rat brain regions. Wounds were made in several CNS areas as indicated in the text and the cavities were filled with Gelfoam. Fifteen days postlesion four animals per region were sacrificed, and trophic and toxic activities were determined in extracts of Gelfoam ( $\square$ ), the tissue that formed the walls of the wound cavity ( $\square$ ), and tissue contralateral to the wound and symmetrical to it (国). These values were compared to those from extract of similar tissue from noninjured controls ( $\square$ ). Neuronotrophic activity was determined using cCG8 neurons and neuronotoxic activity was measured using cLC4 neurons. All determinations were performed in duplicate on each sample pool. Maximum deviations were $\pm 15 \%$ (neuronotrophic) or $\pm 20 \%$ (neuronotoxic) of the values reported.

contralateral to the wound were collected and assayed for neuronotrophic (using cCG8 neurons) and neuronotoxic activities (cLC4 neurons). Similar tissue samples from noninjured animals were used as controls (basal levels). Figure 3 summarizes the results obtained. The basal levels of neuronotrophic activity observed in neocortex were lower than those in any other brain area.
However, injury to the neocortex caused a considerable increase in trophic activity relative to that of noninjured tissue (Fig. $3 a$ ). In contrast, the myelinated fibers of corpus callosum below the parietal cortex had relatively high basal levels of trophic activity that did not appear to increase after injury. Hippocampus, corpus striatum, and cerebellum had basal levels of activity similar to those in corpus callosum, but they increased severalfold 15 days after injury (Fig. $3 a$ ). Neuronotrophic titers in extracts of lumbar spinal cord were two orders of magnitude higher than those in brain, both in normal animals and following lumbar cord hemisection. Work is in progress to investigate the nature of this very high trophic activity for cCG8 neurons.

Similar levels of neuronotoxic activity for cLC4 cells were present in all CNS regions examined, both before injury and 15 days postlesion (Fig. $3 b$ ). The only exception was the myelinated tissue of corpus callosum, where an apparent injury-induced increase in neuronotoxic activity appeared to take place.

Induction of neuronotrophic activity by kainic acid lesion. The trophic activity levels present in the hippocampal formation at various times after bilateral intraventricular injection of kainic acid are given in Figure 4. One hour after injection the trophic activity in the hippocampus was similar to that in noninjected controls. It increased in the following days to reach high values, comparable to those found after mechanical damage, that appeared to level off by 16 days postinjection (Fig. 4).

Survival of striatal fragments implanted in adult rat cortical cavities. Fragments of rat embryo corpus striatum were implanted into cavities made in the entorhinal cortex of adult hosts either on the same day that the cavity was made or after various periods postlesion (see "Materials and Methods"). Surviving implanted tissue was identified 30 days postimplantation by its strong acetylcholinesterase (AChE)-positive reaction (Lewis and Cotman, 1982).

A range of implant survivals was observed and the following arbitrary scale was used for its quantitative

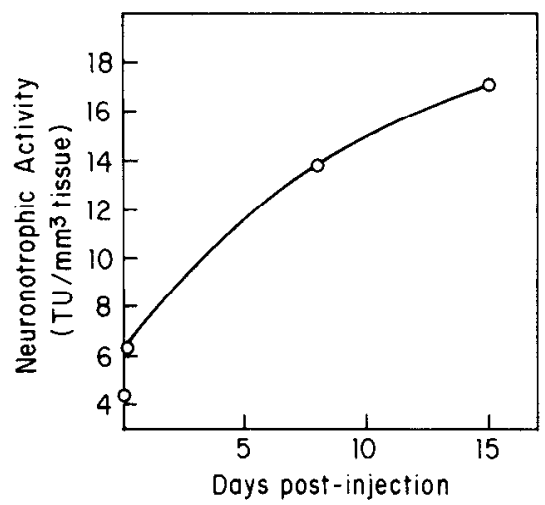

Figure 4. Neuronotrophic activity induced by chemical damage of the adult brain. Three groups of rats were given bilateral intraventricular injections of kainic acid $(0.8 \mu \mathrm{g} /$ ventricle $)$ to destroy areas CA4, CA3, and part of CA1 of the hippocampus. At various times postinjection the neuronotrophic activity in pooled extracts of the damaged hippocampi was determined using cCG8 test neurons. Maximum deviations of duplicate determinations were $15 \%$ of the values reported. 
expression. Survival was graded " 0 " when no surviving striatal cells were observed; " +1 " if only isolated cells survived; " +2 " when surviving groups of AChE-positive cells occupied a volume (deduced from the examination of serial sections) up to about $0.05 \mathrm{~mm}^{3}$ (1000 to 3000 cells); and " +3 " when larger volumes (some of them as large as 4 to $5 \mathrm{~mm}^{3}$ ) of AChE-positive cells were present. For each time point, the normalized implant survival of the group represented the average of the individual scores. Therefore, maximal normalized survival was +3 , the maximum grade given. An example of each of these types of implant is given in Figure 5. AChE-positive fibers grew out of the areas occupied by surviving cells. However, +1 implants did not innervate the host tissue (Fig. 5a), whereas implants with higher scores often recreated the laminar pattern of $\mathrm{AChE}$ staining observed in the control hippocampus (Fig, 5, $c$ and $d$ ) as already observed for transplants in neonatal hosts (Lewis and Cotman, 1982, 1983). Most surviving implants fused with the host tissue, and numerous blood capillaries coursed through them (Fig. 5e). Blood vessels were also observed in the boundary between the tissue and the Gelfoam that filled the wound cavity and, occasionally, in the Gelfoam itself.

The delay in implantation had a profound effect on the survival of the implanted tissue (Fig 6). Nondelayed striatal implants (day 0) did not survive in entorhinal cortical cavities. In fact, in two animals striatal tissue seemed to have a detrimental effect on the host tissue adjacent to the graft because, after sacrifice, the cortical cavity appeared considerably larger than the 20 to 30 $\mathrm{mm}^{3}$ initially ablated. Delayed implantation improved graft survival, and the optimum delay for survival of embryonic corpus striatum into adult cortex was 8 days (Fig. 6). Longer delay periods (16 to 20 days postlesion) actually decreased implant survival down to about onethird of the maximum at 8 days. The implant survival curve closely paralleled the time course of appearance of trophic activity in the tissue immediately adjacent to the cavity (Fig. 6).

\section{Discussion}

Neuronotrophic activity is induced by injury. In previous studies it was observed that neuronotrophic activity accumulates with time in the Gelfoam filling a wound cavity in neonatal rats (Nieto-Sampedro et al., 1982b; Manthorpe et al., 1983). The present work shows that the appearance of neuronotrophic factors in mammalian brain following injury was not restricted to early development. Adult brain responded to injury as developing brain, but the observed increase in trophic activity in the wound cavity (Gelfoam) occurred at a slower rate in adults than in neonates. The increase in trophic activity in the wound cavity was not due to passive ahsorption in the sponge-like Gelfoam of increasing amounts of trophic factors present at a constant concentration in the tissue regardless of injury. Rather, injury appeared to cause the damaged brain tissue to release highly increased levels of these factors (Fig. 1) that were not accompanied by a corresponding increase in Gelfoam protein concentration (Table I). The fact that tissue activity preceded that in Gelfoam suggested that neuronotrophic factors were re- leased by the cells surrounding the wound into the wound cavity where they were absorbed by the Gelfoam sponge.

Maximum trophic activity was found in the tissue immediately adjacent to the wound and it decayed steeply with distance from the injury site (Fig. 2). These results suggest that the injury signals that trigger factor production do not travel far from the injured locus and/or that the factors themselves do not diffuse freely throughout the intercellular space. However, even tissue comparatively far away from the wound contained trophic levels higher than the noninjured basal levels (Fig. 2). The spread of trophic factors from the injury site to the rest of the brain may have taken place by diffusion through the ventricular system, although other mechanisms, such as factor release due to deafferentation or cell death due to ischemia, cannot be excluded.

The levels of injury-induced trophic activity were roughly proportional to the size of the wound (Table III), and maximum activity in adult tissue, for a given injury size, was observed at day 10 postlesion (Fig. 1). The neuronal target specificity profile of the adult brain trophic factors (Fig. 1) was similar to that found in neonatal rat brain (Manthorpe et al., 1983) and in adult sciatic nerve (Lundborg et al., 1982; Longo et al., 1983).

Each of the CNS areas examined exhibited the injury induction phenomenon regardless of whether their preinjury trophic levels were low (e.g., neocortex) or high (e.g., cerebellum) (Fig. 3). One exception was the corpus callosum, where the basal (pre-injury) trophic level was high but injury did not increase it appreciably.

A substance or substances that caused the death of spinal cord neurons on a 24-hr culture assay was previously detected in the fluid accumulating in peripheral nerve regeneration chambers (Lundborg et al., 1982; Longo et al., 1983) and in extracts of Gelfoam filling wounds made in the brain of neonatal rats (Manthorpe et al., 1983). A similar activity was also observed in adult brain and was particularly high in the tissue extracts examined (Fig. $3 b$ ). Brain tissue from noninjured animals had high neuronotoxic titers that were not significantly altered by injury 15 days postlesion (Fig. $3 b$ ). The chemical identity of the toxic activity is unknown. Low molecular weight peptides with growth-inhibitory properties for a wide range of non-neuronal cells are produced by glia (Kagen and Miller, 1980; Kagen et al., 1982) in cultures of embryonic spinal cord (Kagen et al., 1978). The neuronotoxic activity described here showed target cell specificity. At the levels used here, it had no effect on ciliary ganglion neurons and was very toxic for $\mathrm{cLC} 4$ cells. The physiological role, if any, of this apparently noxious factor remains to be defined.

Cellular source of the injury-induced neuronotrophic activity. Glial activation, multiplication, and hypertrophy are reactions to injury characteristic of neural tissue. Induction of neuronotrophic activity by neural damage seems to correlate well with this gliosis. The tissue that forms the walls of a wound cavity is known to contain a proliferating astroglial cell population, and this area also had the highest neuronotrophic titers after injury (Figs. 1 to 3 ). One of the most striking effects of intraventricular injection of kainic acid is the strong glial reaction in the hippocampus that starts within $1 \mathrm{hr}$ of 

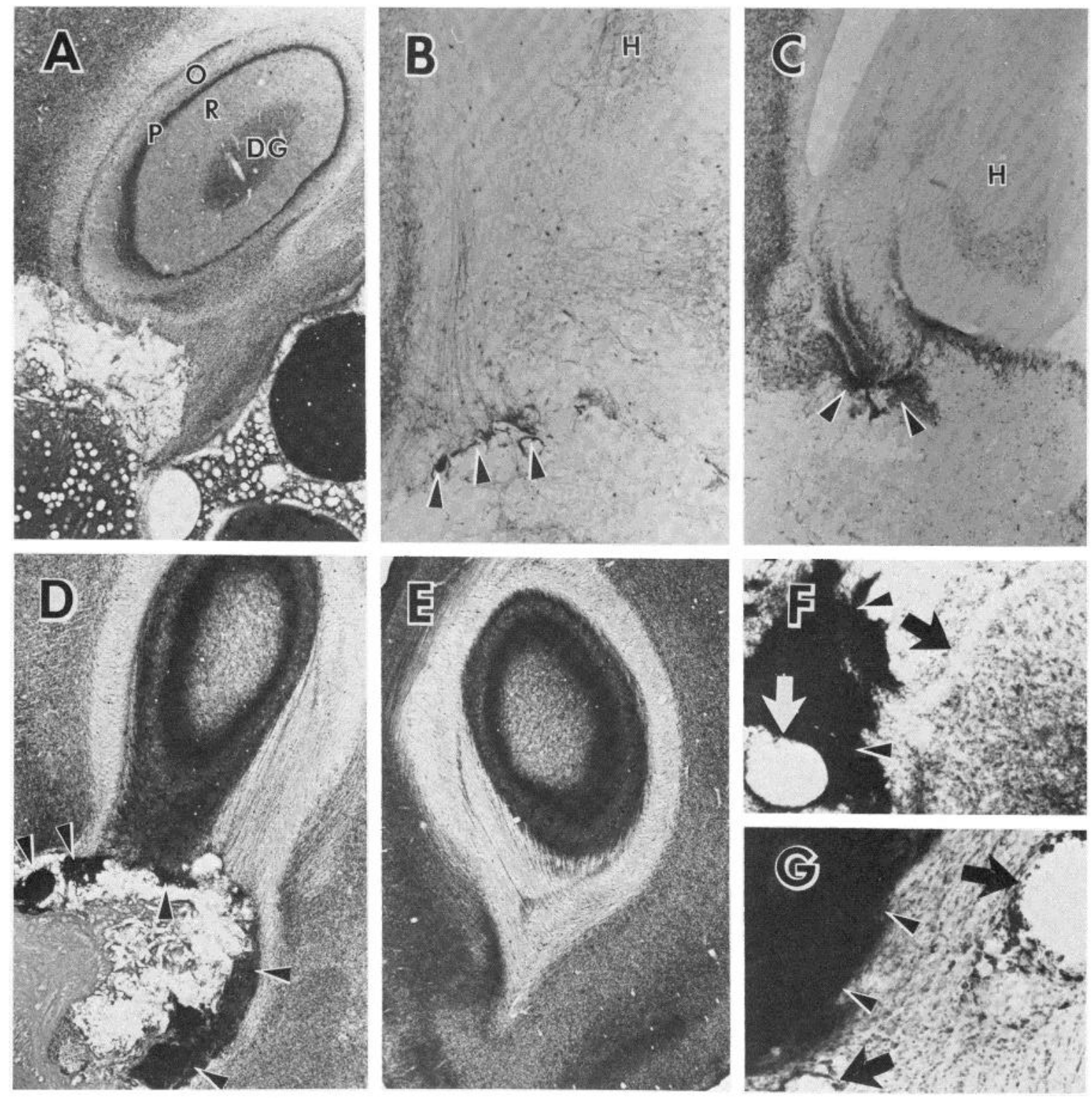

Figure 5. Survival of embryonic rat corpus striatum implanted into wound cavities in the entorhinal cortex of adult hosts. Cavities were filled with saline-moistened Gelfoam. In the course of the same operation the animals also received a unilateral transection of the fimbria, ipsilateral to the cortical cavity, as described under "Materials and Methods." At various times after this operation, several 0.1 - to $2.0-\mathrm{mm}^{3}$ fragments of 18 -day rat embryo corpus striatum (total tissue volume 6 to $9 \mathrm{~mm}^{3}$ ) were implanted into the cortical cavity immediately under the Gelfoam fragment and apposed to the dorsal surface of the hippocampus. Thirty days later the animals were perfused and implant survival, as well as reinnervation of the host, was assessed on horizontal serial sections (50 $\mu \mathrm{m}$ thick) stained for specific AChE (Naik, 1963). Alternate sections were counterstained with cresyl violet. Examples of the various extents of survival observed, graded as indicated in the text, are as follows. A, Grade " 0 ": No implanted cells survive. The host hippocampus has lost its intrinsic septal AChE-positive innervation after fimbria transection. The section was stained for $\mathrm{AChE}$ and counterstained with cresyl violet. Magnification $\times 12$. $P$, pyramidal cells; $D G$, dentate granule cells; $O$, stratum oriens; $R$, stratum radiatum. $B$, Grade “ +1 " survival: Only isolated AChE-positive striatal cells were observed. Fiber outgrowth from these cells was always directed toward the denervated ipsilateral hippocampus $(H)$. AChE stain. Magnification $\times 30$. C, Grade "+2" survival: Groups of AChE-positive striatal cells, occupying a volume of up to $0.05 \mathrm{~mm}^{3}$, were observed. The dorsal surface of the host hippocampus was beginning to be innervated by AChE-positive fibers from the implant. AChE stain. Magnification $\times 15$. $H$, hippocampus. $D$, Grade “+3" survival: Large clumps of implanted AChE-positive cells, occupying up to $5 \mathrm{~mm}^{3}$ in volume, were present. Fibers from these cells are seen invading the dorsal surface of the host hippocampus and, to a lesser extent, the adjacent cortex. AChE stain, cresyl violet counterstain. Magnification $\times 13$. $E$, Noninjured control: Section through the dorsal hippocampus, AChE stain, cresyl violet counterstain. Magnification $\times 13$. F and $G$, Capillaries (arrows) coursed through surviving implants (arrowheads). AChE stain, cresyl violet counterstain. Magnification $\times 23$.

injection of the toxin and reaches a maximum 15 days later (Nadler et al., 1980). Neuronotrophic factor activity rose quickly after kainic acid injection and also reached a plateau 15 days later (Fig. 4). Destruction of the entorhinal cortex with consequent deafferentation of the ipsilateral hippocampus is associated with both a strong 


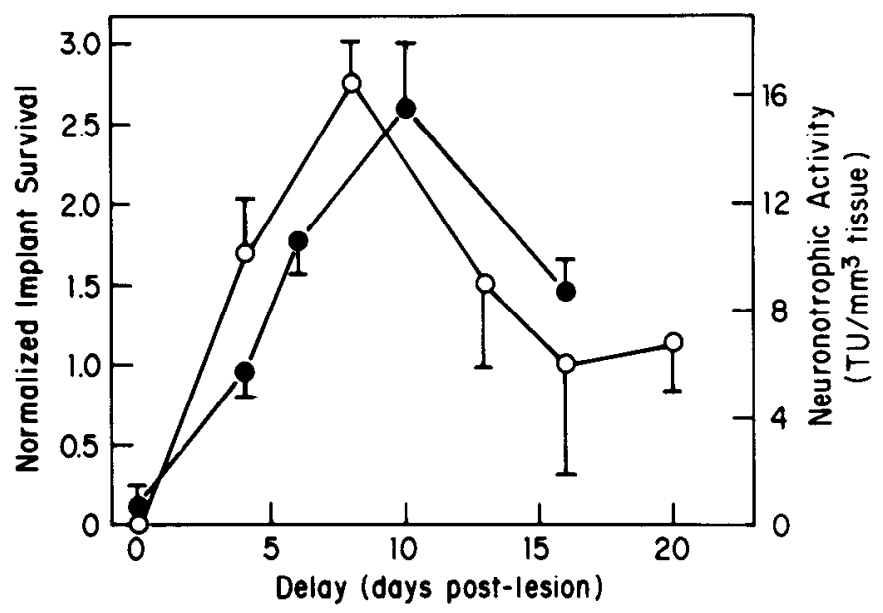

Figure 6. Correlation between striatal implant survival dependent on the delay between cavity making and implantation (O) and appearance of neuronotrophic activity in the injured tissue during the delay (O). Adult rat hosts (four to eight animals/timepoint) received striatal implants into entorhinal cavities, as described under "Materials and Methods." Individual implant survival was scored as indicated in the text and the average survival (and SEM) for each group is represented. Neuronotrophic activity in the tissue around the wound, determined using cCG8 test neurons, was taken from Figure 1. A similar correlation was evident for cSG11 or mDRG test neurons (correlation not shown).

glial reaction (Lynch et al., 1975; Rose et al., 1976; Gall et al., 1979) and an increase in trophic activity (see text under "Influence of distance from the wound on neuronotrophic activity. .."). Although deafferented neurons or endothelial cells could conceivably be additional sources of the released neuronotrophic activity, it seems reasonable that astroglial cells could be the major contributor. Glial cells maintained in vitro are known to release neuronotrophic and neurite-promoting factors into their culture medium (Varon and Somjen, 1979; Varon and Manthorpe, 1982). These considerations implicate glial cells as the source of the injury-induced neuronotrophic activity observed in brain, although a definitive conclusion will depend on future work and, perhaps, the availability of specific antibodies to the trophic factors.

Survival of brain implants in adult hosts: Critical variables. The technique of implantation used in this work was similar to that used in our previous work using neonatal hosts (Lewis and Cotman 1980, 1982; Manthorpe et al., 1983). The survival of embryonic tissue implanted with no delay into a comparatively large cavity aspirated in the cortex of adult hosts has already been described by Kromer and Bjorklund (1980). In our work the cavity destined to receive the implant was filled with saline-soaked Gelfoam and the implanted tissue was placed below the Gelfoam and directly apposed to the host hippocampus. Under these conditions, survival of the implant is likely to depend on the following variables: (i) adequate oxygen and nutrient supply, i.e., vascularization; (ii) absence of lethal concentrations of toxic substances; (iii) availability of appropriate concentrations of trophic substances. Graft survival was associated by Stenevi et al. (1976) with implantation adjacent to a highly vascularized surface. However, the presence of an optimum of survival for implants placed in the wound with a delay of about 8 days cannot be explained by increased vascularization. Once vascularization is established, it seems unlikely that its role in survival would decrease with time. Therefore, if angiogenesis is the only critical variable for transplant survival, the curve in Figure 6 should show an initial increase and then level off, which was not observed.

There was no evidence for changing levels of neuronotoxic activity following injury. On the other hand, the correlation of the optimal transplantation delay with the maximum in the time course of appearance of neuronotrophic activity in the tissue adjacent to the implant (Fig. 6) certainly implies that injury-induced trophic factors contribute to the survival of the implanted tissue. A similar correlation, albeit with a different optimal time, had been observed in neonatal rats (Nieto-Sampedro et al., 1982b; Manthorpe et al., 1983). The hypothesis advanced previously, namely, that the concentration of trophic factors both at the time of implantation and in the days immediately following implantation determine the viability of the grafts, is reinforced by the present results. For neonatal rats, the observed correlation was between implant survival and trophic activity accumulated in the Gelfoam. In the adult, the observed correlation was with activity to the injured tissue immediately adjacent to the wound. The increase in trophic activity in Gelfoam in adults showed a considerable lag with respect to their neonatal counterparts. The faster rate of appearance of trophic factors in Gelfoam in neonates may be related to the presence in newborn brain tissue of larger intercellular spaces that facilitate diffusion of factors into the wound cavity.

In all of these studies neuronotrophic activity was determined on cultured ganglionic and spinal cord neurons, the only cultures currently suitable for quantitative assay of these factors (Varon et al., 1981). A strict correlation between the survival of implants in vivo and induced neuronotrophic activity requires using as test neurons the same type of cells as those that are implanted in vivo, and work to this effect is now in progress.

Induction of high levels of trophic activity in the brain following injury could be a logical part of the tissue repair response. By analogy with the known effects of nerve growth factor on damaged sympathetic neurons (West and Bunge, 1977; Njå and Purves, 1978), high levels of injury-induced central neuronotrophic factors would prevent, for example, the death of axotomized neurons and maintain cells alive until regenerative sprouting allows the neuron to obtain a more stable trophic supply. Alterations in the level of trophic factors may also have a role in pathological cell loss. The lesions caused in the rat brain by injection of kainic acid simulate the brain damage caused by humans by anoxia and epilepsy (Nadler, 1981), and degenerative diseases such as Huntington's chorea (Fibiger, 1978).

Grafted tissue dependence on trophic factors is likely to continue beyond the initial week postimplantation, until integration with the host allows the implant to meet independently its trophic requirements. If this is the case, then an external supply of neuronotrophic factors should enhance implant survival even when delays in implantation are too long for endogenous produc- 
tion to be efficient or when the implant is placed in the wound cavity with no postlesion delay. Work to examine these possibilities is actually is progress and, to a large extent, the eventual therapeutic use of neuronotrophic factors depends on the outcome of this type of experiment.

\section{References}

Bradford, M. M. (1976) A rapid and sensitive method for the quantitation of microgram quantities of protein utilizing the principle of protein-dye binding. Anal. Biochem. 72: 248254.

Cotman, C. W., and J. W. Nadler (1978) Reactive synaptogenesis in the hippocampus. In Neuronal Plasticity, C. W. Cotman, ed., pp. 227-271, Raven Press, New York.

Cotman, C. W., M. Nieto-Sampedro, and E. W. Harris (1981) Synapse replacement in the nervous system of adult vertebrates. Physiol. Rev. 61: 684-784.

Fibiger, H. C. (1978) Kainic acid lesions of the striatum: A pharmacological and behavioral model of Huntington's disease. In Kainic Acid as a Tool in Neurobiology, E. G. McGeer, J. W. Olney, and P. L. McGeer, eds., pp. 161-176, Raven Press, New York.

Gall, C., G. Rose, and G. Lynch (1979) Proliferative and migratory activity of glial cells in the partially deafferented hypocampus. J. Comp. Neurol. 183: 539-550.

Kagen, L. G., and S. L. Miller (1980) Production of spinal cord growth inhibitor by nonneuronal cells. Exp. Neuron. 67: 330345 .

Kagen, L. J., S. L. Miller, and N. Levesanos (1978) Growth inhibitor produced by embryonic spinal cord cells in culture: Studies on its properties and actions. Exp. Neurol. 61: 689704.

Kagen, L. J., S. L. Miller, and M. Pedrotti (1982) Glia-derived growth regulator: Studies on its production and action. Exp. Neurol. 78: 517-529.

Kromer, L. F., and A. Bjorklund (1980) Embryonic neural transplants provide model systems for studying development and regeneration in the mammalian CNS. In Multidisciplinary Approach to Brnin Development, C. di Bluedette, ed., pp. 409-426, Elsevier/North-Holland Biomedical Press, Amsterdam.

Lewis, E. R., and C. W. Cotman (1980) Mechanisms of septal lamination in the developing hippocampus revealed by outgrowth of fibers from septal implants. I. Positional and temporal factors. Brain Res. 96: 307-330.

Lewis, E. R., and C. W. Cotman (1982) Mechanisms of septal lamination in the developing hippocampus analyzed by outgrowth of fibers from septal implants. II. Absence of guidance by degenerative debris. J. Neurosci. 2: 66-77.

Lewis, E. R., and C. W. Cotman (1983) Neurotransmitter characteristics of brain grafts: Striatal and scptal tissues form the same laminated input to the hippocampus. Neuroscience 8: 57-66.

Longo, F. M., M. Manthorpe, and W. Varon (1982) Spinal cord neuronotrophic factors (SCNTFS). I. Bioassay of schwannoma and other conditioned media. Dev. Brain Res. 3: 277294.

Longo, F. M., M. Manthorpe, S. D. Skaper, G. Lundborg, and S. Varon (1983) Neuronotrophic activities in fluid accumulated in vivo within silicone nerve regeneration chambers. Brain Res. 261: 109-117.

Lundborg, G., F. M. Longo, and S. Varon (1982) Nerve regeneration model and trophic factors in vivo. Brain Res. 232: $157-161$.
Lynch, G., G. Rose, C. Gall, and C. W. Cotman (1975) The response of the dentate gyrus to partial deafferentation. In Golgi Centennial Symposium Proceedings, M. Santini, ed., pp. 505-517, Raven Press, New York.

Manthorpe, M., S. D. Skaper, R. Adler, K. B. Landa, and S. Varon (1980) Cholinergic neuronotrophic factors. IV. Fractionation properties of an extract from selected chick embryonic eye tissues. J. Neurochem. 34: 69-75.

Manthorpe, M., S. D. Skaper, and S. Varon (1981) Neuronotrophic factors and their antibodies: In vitro microassays for titration and screening. Brain Res. 230: 295-306.

Manthorpe, M., F. M. Longo, and S. Varon (1982) Comparative features of spinal neuronotrophic factors collected in vitro and in vivo. J. Neurosci. Res. 8: 241-250.

Manthorpe, M., M. Nieto-Sampedro, S. D. Skaper, E. G. Lewis, G. Barbin, F. M. Longo, C. W. Cotman, and S. Varon (1983) Neuronotrophic activity in brain wounds of the developing rat. Correlation with implant survival in the wound cavity. Brain Res. 267: 47-56.

Matthews, D. S., C. Cotman, and G. Lynch (1976) An electron microscopic study of lesion-induced synaptogenesis in the dentate gyrus of the adult rat. I. Magnitude and time course of degeneration. Brain Res. 115: 1-21.

Moore, R. Y., A. Bjorklund, and V. Stenevi (1971) Plastic changes in the adrenergic innervation of the rat septal area in response to denervation. Brain Res. 33: 13-35.

Nadler, J. V. (1981) Kainic acid model of epileptic brain damage. Neurosci. Res. Program Bull. 19: 391-393.

Nadler, J. V., B. W. Perry, and C. W. Cotman (1978) Preferential vulnerability of hippocampus to intraventricular kainic acid. In Kainic Acid as a Tool in Neurobiology, E. G. McGeer, J. W. Olney, and P. L. McGeer, eds., pp. 219-237, Raven Press, New York.

Nadler, J. V., B. W. Perry, C. Gentry, and C. W. Cotman (1980) Degeneration of hippocampal CA3 pyramidal cells induced by intraventricular kainic acid. J. Comp. Neurol. 192: 333359.

Naik, N. T. (1963) Technical variations of Koelle's histochemical method for demonstrating cholinesterase activity. Q. J. Microsc. Sci. 104: 89-100.

Nieto-Sampedro, M., C. Bussineau, and C. W. Cotman (1982a) Turnover of brain postsynaptic densities after selective deafferentation: Detection by means of an antibody to antigen PSD-95. Brain Res. 251: 211-220.

Nieto-Sampedro, M., E. R. Lewis, C. W. Cotman, M. Manthorpe, S. D. Skaper, G. Barbin, F. M. Longo, and S. Varon (1982b) Brain injury causes a time dependent increase in neuronotrophic activity at the lesion site. Science 217: 860861.

Njå, A., and D. Purves (1978) The effects of nerve growth factor and its antiserum on synapses in the superior cervical ganglion of the guinea-pig. J. Physiol. (Lond.) 277: 55-75.

Rose, G., G. Lynch, and C. W. Cotman (1976) Hypertrophy and redistribution of astrocytes in the deafferented dentate gyrus. Brain Res. Bull. 1: 87-92.

Stenevi, V., A. Bjorklund, and N. A. Svendgaard (1976) Transplantation of central and peripheral monoamine neurons to the adult rat brain: Techniques and conditions for survival. Brain Res. 114: 1-20.

Steward, O. (1976) Reinnervation of dentate gyrus by homologous afferents following entorhinal cortical lesions in adult rats. Science 194: 426-428.

Varon, S., and M. Manthorpe (1982) Schwann cells: An in vitro perspective. Adv. Cell. Neurobiol. 3: 35-95.

Varon, S., and G. G. Somjen (1979) Neuron-glia interactions. Neurosci. Res. Program Bull. 17: 66-128.

Varon, S., J. Nomura, J. R. Perez-Polo, and E. M. Shooter 
(1972) The isolation and assay of the Nerve Growth Factor proteins. In Methods and Techniques of Neurosciences, R. Fried, ed., pp. 203-229, Marcel Dekker, Inc., New York.

Varon, S., S. D. Skaper, and M. Manthorpe (1981) Trophic activities for dorsal root and sympathetic ganglionic neurons in media conditioned by Schwann and other peripheral cells.
Dev. Brain Res. 1: 73-87.

West, N., and R. Bunge (1977) Observations on the role of nerve growth factor (NGF) and Schwann cells in the chromatolytic response of sympathetic neurons. Anat. Rec. 187: 747. 